\title{
Target lobe volume reduction and COPD outcome measures after endobronchial valve therapy
}

\author{
Arschang Valipour ${ }^{1}$, Felix J.F. Herth², Otto C. Burghuber ${ }^{1}$, Gerard Criner $^{3}$, \\ Jean-Michel Vergnon ${ }^{4}$, Jonathan Goldin ${ }^{5}$, Frank Sciurba ${ }^{6}$ and Armin Ernst ${ }^{7}$ \\ for the VENT study group
}

\begin{abstract}
Affiliations: 'Dept of Respiratory and Critical Care Medicine, Ludwig-Boltzmann-Institute for COPD and Respiratory Epidemiology, Otto-Wagner-Hospital, Vienna, Austria. ${ }^{2}$ Pneumology and Critical Care Medicine, Thoraxklinik Heidelberg, Germany. ${ }^{3}$ Temple Lung Center, Pulmonary and Critical Care Medicine, Temple University, Philadelphia, PA, ${ }^{5}$ Center for Computer Vision and Imaging Biomarkers, Dept of Radiological Sciences, David Geffen School of Medicine at UCLA, Los Angeles, CA, 'University of Pittsburgh School of Medicine, Pittsburgh, PA, and 'Interventional Pulmonology, St Elizabeth's Medical Center, Boston, MA, USA. 4Pulmonary Medicine, Saint Étienne University Hospital, Saint Étienne, France.
\end{abstract}

Correspondence: A. Valipour, Ludwig-Boltzmann-Institute for COPD, Dept of Respiratory and Critical Care Medicine, Otto-Wagner-Hospital, Vienna, Austria. E-mail: arschang.valipourdwienkav.at

ABSTRACT Endobronchial valve (EBV) therapy may be associated with improvements in chronic obstructive pulmonary disease-related outcomes and may therefore be linked to improvements in the body mass index, airflow obstruction, dyspnoea, exercise capacity (BODE) index.

Data from 416 patients with advanced emphysema and hyperinflation across Europe and USA, who were randomised to $\operatorname{EBV}(n=284)$ or conservative therapy $(n=132)$ were analysed. Quantitative image analysis was used to compare the volume of the targeted lobe at baseline and at 6 months to determine target lobe volume reduction (TLVR).

$44 \%$ of patients receiving EBV therapy (versus $24.7 \%$ of controls) had clinically significant improvements in the BODE index $(\mathrm{p}<0.001)$. BODE index was significantly reduced by mean \pm SD $1.4 \pm 1.8,0.2 \pm 1.3$ and $0.1 \pm 1.3$ points in patients with TLVR $>50 \%, 20 \%-50 \%$ and $<20 \%$, respectively (intergroup differences $\mathrm{p}<0.001$ ), but increased by $0.3 \pm 1.2$ points in controls. Changes in BODE were predicted by baseline BODE and correlated significantly with lobar exclusion and lung volumes at 6 months.

A greater proportion of patients in the treatment group than in the control group achieved a clinically meaningful improvement in BODE index; however, the likelihood of benefit was less than half in both groups. Patients in whom TLVR was obtained had greater improvements in clinical outcomes.

@ERSpublications

Patients treated with EBV were more likely to have a significantly reduced BODE score (44\% treated versus $25 \%$ controls) http://ow.ly/qXRUy

This article has supplementary material available from www.erj.ersjournals.com

Received: Aug 242012 | Accepted after revision: May 202013 | First published online: July 112013

Clinical trial: This study is registered at clinicaltrials.gov with identifier number NCT00129584.

Conflict of interest: Disclosures can be found alongside the online version of this article at www.erj.ersjournals.com

Copyright @ERS 2014 


\section{Introduction}

Endobronchial valve (EBV) therapy attempts to achieve the effects of surgical lung volume reduction $[1,2]$ by selectively occluding the airways supplying the most affected regions of the hyperinflated emphysematous lung, while permitting exhaled gas to escape. Reports of EBV therapy in selected patients with end-stage emphysema have shown significant improvements in lung function and exercise tolerance [3-6]. The most significant functional and subjective improvements are seen when atelectasis develops after the insertion of valves [7, 8]; however, EBV therapy may also be beneficial in the absence of atelectasis [9].

Given that lung volume reduction may be associated with improvements in airflow obstruction, exercise capacity and/or dyspnoea, we hypothesised that the information obtained by quantitative volumetric analysis prior to and after EBV therapy may be associated with changes in other important chronic obstructive pulmonary disease (COPD)-related outcome measures, such as the integrated body mass index, airflow obstruction, dyspnoea and exercise capacity (BODE) index.

The BODE index is a multidimensional grading system, which has been shown to be better than forced expiratory volume in $1 \mathrm{~s}$ (FEV1) alone in predicting the risk of future COPD exacerbations, hospitalisations and/or death in patients with COPD [10-13]. The BODE index has been shown to be responsive to interventions such as pulmonary rehabilitation [14] and lung volume reduction surgery [15-17]. Furthermore, there is evidence that the BODE index has greater predictive value than individual outcome measures alone [18]. Thus, changes in BODE could serve as a measure of treatment success and should correlate with other important clinical outcomes in COPD patients undergoing EBV therapy. The Endobronchial Valve for Emphysema Palliation Trial (VENT) provides an ideal dataset to examine the relationship of changes in lung volume reduction to BODE index as it compared an active intervention with optimal medical therapy in a randomised trial. Individual data sets from USA [3] and European [19] VENT cohorts have already been published, and in these reports the analyses were confined to single outcome measures. In the analysis presented here, we have used the complete VENT dataset to examine the impact of EBV therapy upon the multidimensional BODE index and its relationship with target lobar volume reduction measured 6 months after the procedure.

\section{Methods}

The study group consisted of all patients with emphysema who participated in the USA and European VENT studies. The clinical protocols have identical inclusion/exclusion criteria, efficacy variables and adverse event collection. Details of the trial design and study eligibility criteria for VENT have been reported previously $[18,20]$. Briefly, patients were randomly assigned in a ratio of 2:1 to receive EBV treatment along with optimised medical care or optimised medical care alone. All patients provided written informed consent as approved by the ethics committee overseeing each clinical site.

Clinical effectiveness measures were obtained 6 months after the intervention. These included FEV1, the 6-min walk test, cycle ergometry workload and health-related quality of life (assessed using the St George's Respiratory Questionnaire (SGRQ)). Safety was evaluated by determining the rates of major complications (including death), a composite of pulmonary adverse events, cardiovascular events and implant-related adverse events (online supplementary table E1).

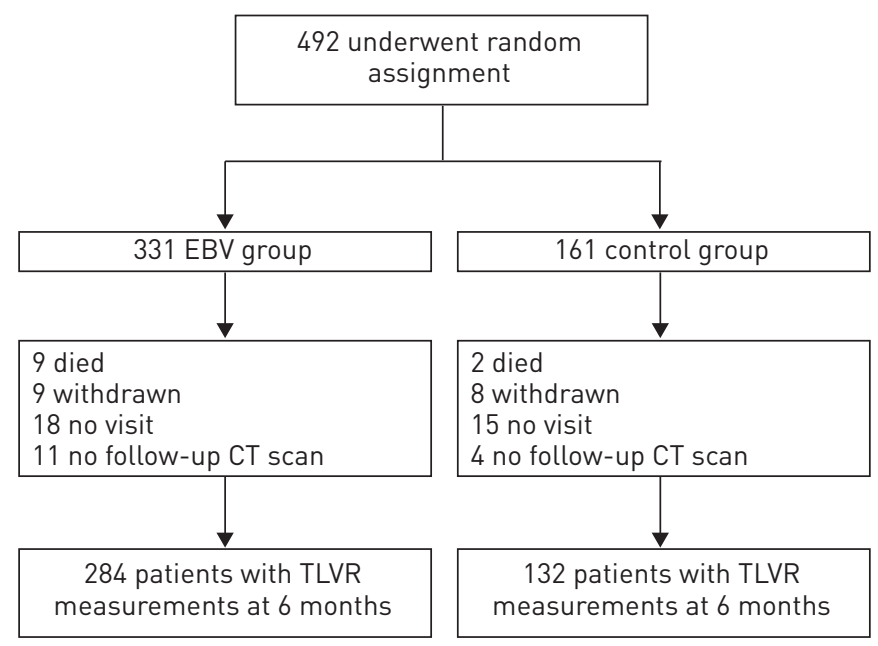

FIGURE 1 Study flow chart. EBV: endobronchial valve; CT: computed tomography; TLVR: target lobe volume reduction. 
TABLE 1 Characteristics of patients and controls at baseline

Total sample

Treatment group

Control group

\begin{tabular}{|c|c|c|c|c|c|c|}
\hline & & & \\
\hline & & $\begin{array}{l}\text { Total treatment } \\
\text { group }\end{array}$ & $\begin{array}{l}\text { Complete } \\
\text { fissure }\end{array}$ & $\begin{array}{l}\text { Incomplete } \\
\text { fissure }\end{array}$ & p-value & \\
\hline Subjects n & 416 & 284 & 110 & 174 & & 132 \\
\hline Male $\%$ & 62 & 63 & 63 & 63 & 0.535 & 62 \\
\hline BMI $\mathrm{kg} \cdot \mathrm{m}^{-2}$ & $24.4 \pm 3.9$ & $24.4 \pm 4.0$ & $24.9 \pm 3.9$ & $24.0 \pm 4.1$ & 0.073 & $24.3 \pm 3.6$ \\
\hline Smoking duration years & $36.0 \pm 8.9$ & $36.2 \pm 9.1$ & $35.3 \pm 8.6$ & $36.7 \pm 9.4$ & 0.207 & $35.6 \pm 8.5$ \\
\hline FVC L & $2.63 \pm 0.80$ & $2.63 \pm 0.78$ & $2.53 \pm 0.75$ & $2.69 \pm 0.79$ & 0.070 & $2.64 \pm 0.84$ \\
\hline FVC \% pred & $0.67 \pm 0.15$ & $0.66 \pm 0.15$ & $0.64 \pm 0.16$ & $0.68 \pm 0.14$ & 0.034 & $0.67 \pm 0.17$ \\
\hline$F_{1} V_{1} / F V C$ & $0.34 \pm 0.07$ & $0.35 \pm 0.07$ & $0.35 \pm 0.07$ & $0.34 \pm 0.07$ & 0.160 & $0.34 \pm 0.07$ \\
\hline Total lung capacity L & $7.66 \pm 1.44$ & $7.68 \pm 1.44$ & $7.66 \pm 1.50$ & $7.69 \pm 1.41$ & 0.850 & $7.61 \pm 1.44$ \\
\hline Residual volume $\mathrm{L}$ & $4.84 \pm 1.15$ & $4.87 \pm 1.14$ & $4.94 \pm 1.22$ & $4.83 \pm 1.08$ & 0.415 & $4.78 \pm 1.19$ \\
\hline IC/TLC & $0.23 \pm 0.07$ & $0.23 \pm 0.07$ & $0.23 \pm 0.07$ & $0.23 \pm 0.06$ & 0.759 & $0.23 \pm 0.07$ \\
\hline Cycle ergometry W & $47.1 \pm 22.9$ & $46.8 \pm 22.9$ & $53.4 \pm 24.2$ & $44.8 \pm 21.7$ & 0.076 & $47.7 \pm 23.0$ \\
\hline \multirow{2}{*}{\multicolumn{7}{|c|}{$\begin{array}{l}\text { Proportions of target } \\
\text { lobes per lung } \%\end{array}$}} \\
\hline & & & & & & \\
\hline Left lung & 38.4 & 40.1 & 61.8 & 26.5 & $<0.001$ & 34.9 \\
\hline Right lung & 61.6 & 59.9 & 38.2 & 73.5 & $<0.001$ & 65.1 \\
\hline $\begin{array}{l}\text { Patients with complete } \\
\text { fissures } \%\end{array}$ & 39.1 & 38.6 & 100.0 & 0.0 & & 40.1 \\
\hline
\end{tabular}

Data are presented as mean $\pm S D$, unless otherwise stated. $p$-values were obtained by comparison of means by t-tests for independent samples, comparison of frequencies by crosstabs and Chi-squared tests. BMI: body mass index; FEV1: forced expiratory volume in $1 \mathrm{~s} ; \%$ pred: \% predicted; FVC: forced vital capacity; IC: inspiratory capacity; TLC: total lung capacity; BODE: BMI, airflow obstruction, dyspnoea and exercise capacity; mMRC: modified Medical Research Council; SGRQ: St George's Respiratory Questionnaire.

High-resolution computed tomography

A computer-based quantitative analysis of standardised multirow detector computed tomography (CT) performed on the $10-\mathrm{mm}$ reconstructed image set was analysed at a core laboratory to provide quantitative indices of lobar emphysema severity and lobar volumes and to identify the target lobe. The methods for evaluating the images have been reported previously [20]. When choosing the target lobe, both the degree of emphysema and heterogeneity were taken into account (a thorough description of the algorithm used has already been published [3]). In the case of the right lung, the middle lobe was ignored. Fissure integrity was analysed on the thin-section $(<3 \mathrm{~mm})$ reconstructed image dataset, and defined as the completeness of the fissure ( $>90 \%$ of the fissure present on thin-slice high-resolution CT) on at least one axis, as classified by the consensus of two independent blinded readers at the core laboratory. Quantitative image analysis by the core laboratory was used to measure and compare the volume of the targeted lobe at baseline and at 180 days in order to determine the target lobe volume reduction (TLVR). The CT scan obtained at 6 months was further used to determine lobar exclusion, i.e. correct placement of the valves in the targeted airways with the intention to isolate a lobe from ventilation.

\section{Procedure}

Bronchoscopy and periprocedural preparations were performed as previously described [20]. Valves were placed unilaterally in lobar, segmental or subsegmental bronchi based on individual anatomy with the intention of completely isolating the target lobe. The valve used in this study was a one-way silicone duckbill valve (Zephyr EBV; Pulmonx, Redwood City, CA, USA). The valve is available in two sizes, spanning airway diameters of $4.0-7.0 \mathrm{~mm}$ and $5.5-8.5 \mathrm{~mm}$. 
TABLE 2 Clinical, functional and radiological outcomes presented as percentage of population in patients treated with endobronchial valve therapy and controls at 6 months according to fissure status

Treatment group

Control group

\begin{tabular}{|c|c|c|c|c|}
\hline & & & & \\
\hline & Complete fissure & Incomplete fissure & p-value & \\
\hline Subjects $\mathrm{n}$ & 110 & 174 & & 132 \\
\hline \multicolumn{5}{|l|}{ Radiological outcomes } \\
\hline TLVR $20-50 \%$ & 22.0 & 15.3 & & 2.0 \\
\hline TLVR $\leqslant 20 \%$ & 30.1 & 67.3 & & 82.2 \\
\hline Missing & 15.4 & 13.3 & & 15.8 \\
\hline 6-min walk distance $(26 \mathrm{~m})$ & 45.3 & 42.1 & 0.352 & 35.5 \\
\hline SGRQ (4 points) & 41.7 & 44.4 & 0.394 & 30.2 \\
\hline mMRC (1 point) & 35.7 & 32.8 & 0.385 & 14.7 \\
\hline BODE index (1 point) & 41.0 & 46.9 & 0.242 & 24.7 \\
\hline
\end{tabular}

Data are presented as \%, unless otherwise stated. p-values were obtained by comparison of frequencies by crosstabs and Chi-squared tests. TLVR: target lobar volume reduction; FEV1: forced expiratory volume in $1 \mathrm{~s} ; \%$ pred: \% predicted; SGRQ: St George's Respiratory Questionnaire; mMRC: modified Medical Research Council dyspnoea scale; BODE: body mass index, airflow obstruction, dyspnoea and exercise capacity scale.

\section{Statistical analysis}

Statistical analysis was performed using SPSS Statistics 17.0 (IBM, Armonk, NY, USA). Simple descriptive statistics were calculated for qualitative outcomes and standard measures were calculated for continuous variables. Unless otherwise indicated, data are presented as mean $\pm \mathrm{SD}$. Baseline characteristics for patients in the treatment group were analysed according to the presence or absence of complete interlobar fissures. Outcomes of interest were further presented according to TLVR cut-offs of $<20 \%, 20-50 \%$ and $>50 \%$. These thresholds were chosen on the basis of cluster analysis and are consistent with recent reports [21]. Group differences according to continuous data were evaluated using two-sample t-tests for one variable, and the generalised linear model for multivariate analyses. Box's $M$ test was applied to check equality of covariance matrices whenever required. For categorical data, crosstabs were generated and frequencies were analysed via the Pearson Chi-squared test or Fisher exact test. Minimal clinically important differences were defined according to recommended cut-offs for FEV1 [22], SGRQ [23], modified Medical Research Council dyspnoea scale [23] and 6-min walking test [24]. For the BODE index, a reduction of 1 point was considered clinically relevant [11]. Pearson's correlation coefficient was used for interval-scaled data as a measurement of the bivariate linear relationship. Multinomial logistic regression was applied to check the effects of a set of predictor variables (factors (scale) or covariates (ordinal)) on a dependent variable (ordinal variable with more than two categories).

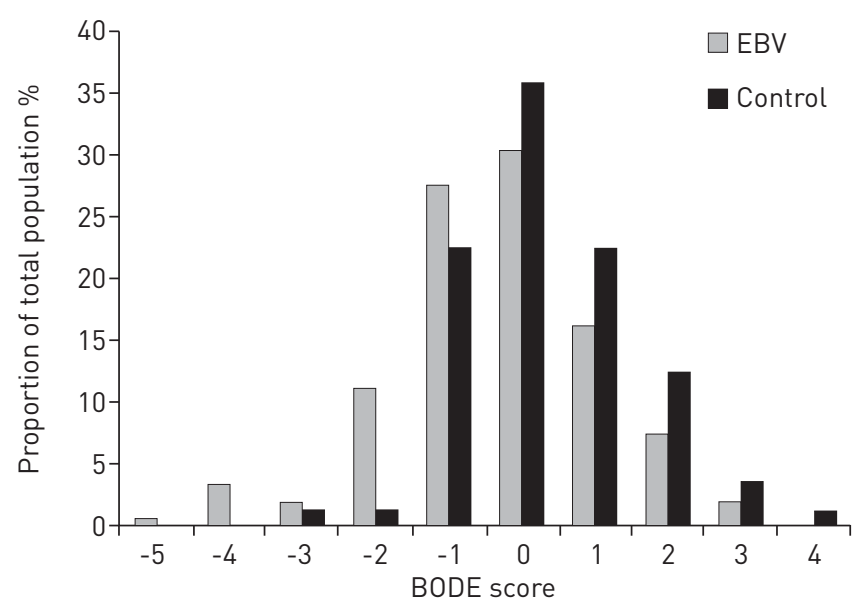

FIGURE 2 Distribution of body mass index, airflow obstruction, dyspnoea and exercise capacity (BODE) scores at 6 months in endobronchial valve (EBV)-treated patients and controls. 
TABLE 3 Baseline predictors of change in body mass index, airflow obstruction, dyspnoea and exercise capacity (BODE) score at 6 months using stepwise linear regression analysis

\begin{tabular}{lccc} 
& B & SE & p-value \\
\hline BODE index baseline & -3.40 & 0.06 & $<0.001$ \\
Age & -0.005 & -0.078 & 0.938 \\
Sex & 0.005 & 0.071 & 0.943 \\
Residual volume & 0.097 & 1.468 & 0.144 \\
Baseline destruction score & & & \\
$\quad$ Target lobe & -0.098 & -1.512 & 0.132 \\
$\quad$ psilateral lobe & 0.046 & 0.705 & 0.482 \\
Target lobe heterogeneity & -0.087 & -1.355 & 0.177 \\
Fissure status & -0.056 & -0.873 & 0.384 \\
\hline
\end{tabular}

\section{Results}

A total of 492 patients were enrolled across Europe $(n=171)$ and the USA $(n=321)$. For the purpose of this analysis, only patients with follow-up CT scans at 6 months were included. Thus, 416 patients were finally included in this study analysis (fig. 1). There were no significant differences in baseline characteristics between those included and excluded (data not shown).

Of the 416 patients included, 284 received EBVs with optimised medical care (treatment group) and 132 received optimised medical care alone (controls). All patients were receiving bronchodilator therapy, $50 \%$ received inhaled corticosteroids and $61 \%$ received long-term oxygen treatment. There were no statistically significant differences in baseline characteristics between the treatment and control arms (table 1). Within the treatment group, significantly more patients with complete fissures on pretreatment CT scans were treated in the left lung than patients with incomplete fissures $(\mathrm{p}<0.001)$.

\section{TLVR and COPD-related outcomes at 6 months}

TLVR was significantly higher in the total group of patients receiving EBV therapy at 6 months than in controls $(-242 \pm 302 \mathrm{~mL}$ versus $0.5 \pm 74 \mathrm{~mL}, \mathrm{p}<0.001)$. Of those randomised to the treatment group, $32 \%$ of patients with complete fissures showed a TLVR $>50 \%$ at 6 months following intervention, $22 \%$ a TLVR between $20 \%$ and $50 \%$, and $30 \%$ a TLVR $\leqslant 20 \%$ (table 2 ). In contrast, only $4 \%$ of patients with incomplete fissures had a TLVR $>50 \%$ and the majority of patients $(67 \%)$ had TLVR $\leqslant 20 \%(\mathrm{p}<0.001$ for intergroup differences).

The distribution of BODE scores at 6 months in EBV-treated patients and controls is displayed in figure 2. $44 \%$ of patients randomised to EBV treatment compared to $24.7 \%$ of controls had improvement in BODE index at 6 months $(\mathrm{p}<0.001)$. In contrast, worsening of BODE was observed in $39 \%$ of controls compared with $25 \%$ of patients in the treatment arm $(\mathrm{p}<0.001)$. Patients with TLVR $>50 \%$ at 6 months demonstrated greater improvements in lung function, exercise capacity, quality of life, dyspnoea and BODE index compared to the other groups (online supplementary table E2). Improvements in the BODE index of $\geqslant 1$ point were observed in $67 \%, 37 \%$ and $41 \%$ of patients with TLVR $>50 \%$, TLVR $20-50 \%$ and TLVR $<20 \%$, respectively ( $\mathrm{p}=0.011$ for intergroup differences). There were no statistically significant differences with respect to the percentage of patients with either improvement or worsening of BODE index between centres with fewer than five, between five and 10, and those with $\geqslant 10$ EBV-treated patients in the study (online supplementary table E3). These findings did not change after correction for the prevalence of complete versus incomplete fissures.

\section{Predictors of a successful outcome}

We conducted linear regression analysis using a number of variables to determine baseline predictors of change in BODE index at 6 months, including age, sex, baseline BODE, fissure integrity, target lobe heterogeneity and baseline destruction scores of the treated and untreated ipsilateral lobe. Baseline BODE index score was the only independent predictor of changes in BODE index at 6 months (table 3). When removing baseline BODE from this analysis, baseline destruction score of the target lobe was revealed as the only independent predictor of change in BODE at 6 months (online supplemementary table E4).

\section{Correlates of a successful outcome}

At 6 months only $55.9 \%$ of the EBV-treated patients demonstrated CT evidence of lobar exclusion. A post hoc analysis was performed to investigate factors that were associated with changes in BODE index at 
TABLE 4 Correlates of change in body mass index, airflow obstruction, dyspnoea and exercise capacity (BODE) score at 6 months using stepwise linear regression analysis

\begin{tabular}{lccc} 
& B & SE & p-value \\
\hline Lobar exclusion & -0.823 & 0.210 & $<0.001$ \\
Change in residual volume & 0.762 & 0.175 & $<0.001$ \\
Change in total lung capacity & 0.593 & 0.206 & 0.004 \\
Age & 0.019 & 0.297 & 0.767 \\
Sex & -0.107 & -1.650 & 0.101 \\
Change in IC/TLC ratio & -0.058 & -0.687 & 0.493 \\
Target lobar volume reduction & 0.115 & 1.437 & 0.152 \\
Target lobe & -0.075 & -1.122 & 0.263 \\
\hline
\end{tabular}

IC: inspiratory capacity; TLC: total lung capacity.

6 months using changes in lung volumes, target lobar volume reduction and lobar exclusion as potential correlates of a successful outcome (table 4). Changes in BODE index were associated with lobar exclusion, changes in residual volume and total lung capacity. Both patients with incomplete and those with complete fissures had significantly larger improvements in BODE index in the presence of lobar exclusion (fig. 3).

\section{TLVR and safety}

The relationship between treatment response and safety was assessed by analysing individual adverse events at 6 months. There were no significant differences in mortality between the intervention and control group (data not shown). The rate of pulmonary/thoracic adverse events, however, was higher in EBV-treated subjects compared with controls (table 5). This difference was mainly driven by the following subcategories of adverse events: haemoptysis ( $42 \%$ of EBV subjects compared with $2 \%$ of control subjects, $\mathrm{p}<0.0001$ ) and noncardiac chest pain ( $16 \%$ of EBV subjects compared with $3 \%$ of control subjects, $p=0.0018)$. There were no statistically significant differences in cumulative cardiovascular, pulmonary or implant-related adverse events groups between patients with complete and those with incomplete fissures. With respect to individual adverse events, however, there was a significantly higher pneumothorax rate $(10.2 \%)$ in patients with TLVR $>50 \%$ compared with the other groups (1.2\% pneumothorax rate in the TLVR $20-50 \%$ group and $0.6 \%$ pneumothorax rate in TLVR $<20 \%$ group) (online supplementary table E5). Of these, one patient with a prolonged pneumothorax underwent surgical oversew of the air leak. Removing these data from the analysis did not alter outcomes.

\section{Discussion}

One-way EBV therapy is intended to produce volume reduction, mimicking the health benefit effects of surgical lung volume reduction with overall lower morbidity and mortality [25]. Using data from two large randomised clinical trials of EBV therapy in patients with severe emphysema, the present analysis revealed a

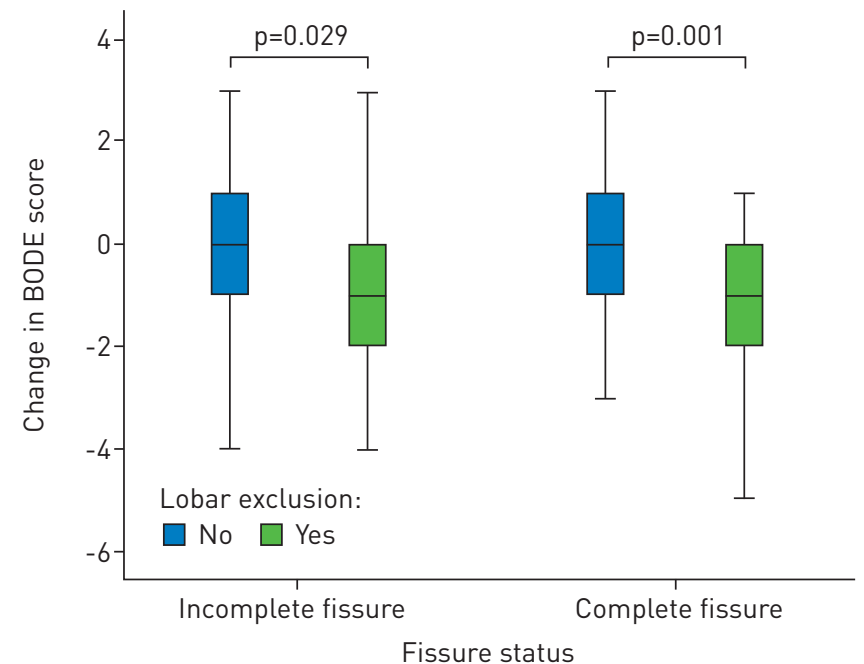

FIGURE 3 Boxplot of change in body mass index, airflow obstruction, dyspnoea and exercise capacity (BODE) score at 6 months in patients with and without lobar exclusion according to fissure status. 
TABLE 5 Most important adverse events (serious and non-serious) at 6 months according to fissure status

Treatment group

Control group

\begin{tabular}{lccc} 
& Complete fissure & Incomplete fissure & p-value \\
\hline Subjects $n$ & 110 & 174 & 132 \\
Pulmonary/thoracic adverse events & 71 & 72 & 51 \\
$\quad$ Pneumothorax & 4.1 & 2.0 & 0.547 \\
$\quad$ Respiratory failure & 4.1 & 3.6 & 0.356 \\
Implant-related adverse events & 13 & 2.6 & 0.522 \\
$\quad$ Pneumonia distal to valve & 6.5 & 6.1 & 0.378 \\
Cardiovascular adverse events & 4.1 & 0.157 & NA \\
\hline
\end{tabular}

Data are presented as \%, unless otherwise stated. NA: not applicable.

relationship between TLVR and clinically meaningful changes in relevant COPD outcome measures, such as the multidimensional BODE index. These changes were predominantly observed in the presence of complete fissures and lobar exclusion.

The BODE index, evaluated at baseline in clinical trials, has been shown to exhibit greater predictive value than its individual components with respect to quality of life, exacerbation rates, morbidity and mortality in patients with COPD $[10,12,13]$. Furthermore, a recent study demonstrated that longitudinal changes in the BODE index, and not FEV1, were independently associated with an increased risk of dying [19]. Conversely, a few intervention studies have suggested that the BODE index changes after therapeutic intervention and that this change appears to be related to subsequent health outcomes. IMFELD et al. [15] found that improvement in the BODE index 3 months after surgical lung volume reduction was associated with lower subsequent mortality. Similar findings have been observed in a small cohort of patients who underwent EBV therapy for emphysema. DE OLIVEIRA et al. [26] demonstrated smaller improvements in BODE at 3 months following EBV implantation. However, these studies have been limited by small numbers and/or lack of controls.

Improvements in BODE index in the present cohort were predicted by baseline BODE index, an observation that is consistent with recent findings from bronchoscopic lung volume reduction trials [27]. These findings suggest that improvements in ventilatory mechanics after EBV may have a higher impact in patients with more severe disease at baseline, a hypothesis that is further supported by post hoc evidence of an independent association between changes in lung volumes and BODE index at 6 months. However, clinically meaningful improvements in BODE in the present report were seen predominantly in the subgroup of patients who had lobar exclusion at 6 months and thus developed $>50 \%$ lobar volume reduction. The majority of these patients $(67 \%)$ had an improvement in BODE index of $\geqslant 1$ point. Results from lung volume reduction surgery in the National Emphysema Treatment Trial [11] have shown that $32 \%$ of patients who underwent lung volume reduction surgery similarly had a 1-point improvement in BODE index at 6 months following randomisation. Importantly, this change in BODE was associated with a significant $43 \%$ decrease in subsequent mortality in that report. Thus, the magnitude of improvement in BODE index in patients with $>50 \%$ lung volume reduction is in a range suggestive of potential benefits such as a reduction in mortality. This hypothesis is further supported by two recent studies that were able to demonstrate long-term survival benefits in the presence of significant lung volume reduction [7, 28].

It remains unclear whether EBV-treated patients may experience clinical benefits in the absence of atelectasis. HOPKINSON et al. [9] demonstrated improvements in lung function, dynamic hyperinflation, oesophageal pressure-time product and a reduction in static compliance in a group of 19 patients who underwent valve treatment. Improvements in exercise capacity were independently associated with improvements in diffusing capacity and with reductions in static lung volumes, both in the presence and absence of atelectasis. This suggests that valve insertion may direct airflow into less affected areas of the lung, reducing dynamic hyperinflation during exercise [9]. This is of particular importance, as the daily physical activity of patients with COPD is mainly associated with dynamic hyperinflation, regardless of severity classification [29]. However, when the patients with atelectasis (defined as a change in the position of the interlobar fissure adjacent to the targeted area) in the report of HopKINSON et al. [9] were excluded, the exercise improvement in the remaining group was no longer significant. 
It has to be acknowledged that the majority of patients in the present report did not have clinically relevant lobar volume reduction. A number of factors may have prevented benefits in a larger proportion of the treated patient population. Recent studies suggest that fissure status is an important predictor of treatment response [18]. Incomplete fissures suggest collateral ventilation across lobes, a phenomenon that is more common in emphysematous than in normal lungs [30]. There is evidence that the interlobar fissures are more often incomplete on the right than on the left side of the lung [31], thus left-side treated patients were more likely to develop greater TLVR. More recently, a catheter-based system (Chartis; Pulmonx) has been developed, which enables real-time assessment of collateral ventilation and, thus, can be used to predict lobar volume reduction in response to valve placement $[32,33]$.

However, the success of valve treatment may largely depend on lobar exclusion (i.e. all airways to the lobe are blocked by EBVs). A post hoc stepwise linear regression analysis identified lobar exclusion as the strongest independent correlate of changes in BODE index at 6 months. This observation is further supported by a recent report from NINANE et al. [34]. The authors intended to place valves bilaterally in the upper lobes. Per protocol, one segment of each upper lobe was not treated to achieve incomplete occlusion of the upper lobes. Using this approach, the authors reported a mean \pm SD $7.3 \pm 9 \%$ TLVR at 3 months, with no clinically meaningful changes in lung function. Thus, one could argue that their entire study cohort matches the low-TLVR subgroup in our analysis. Moreover, a recent study by EBERHARDT et al. [35] confirms that a unilateral lobar approach with lobar exclusion is superior to a bilateral approach with incomplete lobar exclusion with respect to improvements in lung function and exercise capacity.

A number of methodological issues need to be addressed. The present report is an intention-to-treat analysis. Thus, outcomes data presented at 6 months included patients with incomplete lobar exclusion due to bronchoscopic valve removal because of adverse events or migration of valves, coughing up valves, and/ or technical failure to place valves in the first place. Furthermore, lobar exclusion was assessed using CT analysis rather than bronchoscopic inspection at follow-up, and it yet remains to be established whether one is superior to the other. The absence of a sham procedure and the lack of longer follow-up are other potential limitations in the study design. Finally, with low overall mortality in the present report, we were unable to determine whether changes in the BODE index were in fact associated with actual long-term prognosis. Nevertheless, the consistent relationship between TLVR and clinical and functional parameters, and the magnitude of effects in patients with more than 50\% TLVR, support a true intervention effect. As all patients and investigators were blinded to the magnitude of lobar volume collapse, one might speculate that results in lobar nonresponders (TLVR $<20 \%$ ), which are similar to controls in most outcome measures, may be comparable to those with sham procedures. Furthermore, we have to acknowledge that patients with $>50 \%$ TLVR had a higher likelihood of developing a pneumothorax, a phenomenon which is most likely due to sheer stress on the ipsilateral adjacent untreated lobe. The majority of these events resolved with observation or chest tube placement, and only two patients reportedly underwent surgical air leak closure. As these patients experience substantial lobar volume reduction with large clinical benefits, the risk of developing a pneumothorax appears to be linked to the likelihood of a positive clinical response at 6 months [18].

In summary, the current study has shown that a minority subgroup of patients in the VENT trial experienced substantial TLVR with subsequent important health outcomes of patients with emphysema. Predictors of success identified in the present report need to be considered in the design of future valve treatment trials for emphysema.

\section{Acknowledgements}

We would like to thank the VENT study investigators and clinical sites for their diligent efforts in recruiting and following-up the patients participating in this study, and Andrea Schrott (StatistikAmbulanz KG, Leobendorf, Austria) for her contributions related to statistical evaluation of the data. Editing assistance was provided by Archimed Medical Communication (Zofingen, Switzerland).

VENT Study Research Group members are as follows. Clinical centres: A. End, F. Schneider and W. Klepetko (Allgemeines Krankenhaus Wien, Vienna, Austria); F.Stanzel, N.Weber and K. Haeussinger (Asklepios Fachkliniken München-Gauting, Gauting, Germany); S. Gasparini and S. De Luca (Azienda Ospedaliera Umberto I, Ancona, Italy); E. Golden, M. Smith and G. Williams (Baptist Memorial Hospital, Memphis, TN, USA); A. Ernst, D. Feller-Kopman, R. Garland, S. Ashiku and M. DeCamp (Beth Israel Deaconess Medical Center, Boston, MA, USA); G. Ferguson and T. Murphy Thompson (Botsford Hospital, Livonia, MI, USA); R. McKenna Jr, C. Geaga and D. Kusuanco (Cedars-Sinai Medical Center, Los Angeles, CA, USA); CH. Pison, B. Wuyam, G. Ferretti, I. Vivodtzev and C. Righini (Centre Hospitalier Universitaire de Grenoble, Grenoble, Switzerland); F. Lebargy, G. Deslee and S. Dury (Centre Hospitalier Universitaire de Reims, Reims, France); C. Witt and B. Schmidt (Charité Campus Mitte, Berlin, Germany); J. Gonzalez-Bermejo, V. Trosini-Desert, T. Similowski, C. Beigelman and M.H. Becquemin (Groupe Hospitalier Pitié Salpétrière, Paris, France); M. Simoff and R. Almario (Henry Ford Hospital, Detroit, MI, USA); H. Mal, A. Marceau, M. Fournier, O. Brugière and G. Dauriat (Hôpital Beaujon, Paris, France); C. Marquette, S. Leroy, T. Perez and N. Bautin (Hôpital Calmette, Lille, France); G. Massard, R. Kessler, A. Charloux, M. Y. Jeung and A. Jory (Hôpital Civil, Strasbourg, France); J. F. Muir, 
C. Viacroze, D. Benhamou, A. Cuvelier and L. Molano (Hôpital de Bois Guillaume, Rouen, France); B. Degano, C. Hermant, S. Pontier, J. Rami and V. Chabbert (Hôpital Larrey, Toulouse, France); J.M. Vergnon, C. Veyret, F. Costes aned L. De Matos (Hôpital Nord, Saint Étienne, France); M. Febvre, C. Chouaid and B. Lebeau (Hôpital Saint-Antoine, Paris, France); C. Pinet, H. Dutau, P. Thomas, M. Badier and J.Y. Gaubert (Hôpital Sainte Marguerite, Marseille, France); A. Xaubet, A. Torres, C. Agustí and J. Barberà (Hospital Clínic de Barcelona, Barcelona, Spain); A. Agustí, B. Togores, F. Renom, J. Sauleda and R. Ramos (Hospital Universitari Son Dureta, Palma Mallorca, Spain); S. Nathan, S. Ahmad, L. Collazo and E. Battle (Inova Fairfax Institute of Research, Falls Church, VA, USA); E. Hecker, J. Volmerig and T. Jahn (Klinikum Bremen-Ost, Bremen, Germany); J. Ficker, M. Wagner and T. Fink (Klinikum Nürnberg, Nuremberg, Germany); J. Egan and J. Coyle (Mater Misericordiae University Hospital, Dublin, Ireland); E. Edell, D. Midthun, J. Utz, B. Andrist and K. Meiras (Mayo Clinic, Rochester, MN, USA); C. Strange, G. Silvestri and E. Williams-Cummings (Medical University of South Carolina, Charleston, SC, USA); E. Freilich, D. Amin, J. Masson, D. Orlando and L. Morgan (Morton Plant, Clearwater, FL, USA); R. Bowler, C. Wheeler and K. Mitchell (National Jewish Medical and Research Center, Denver, CO, USA); R. Maxfield, M. Ginsburg, P. Jellen and F. Brogan (New York-Presbyterian Hospital, New York, NY, USA); A. Valipour, R. Kohansal and C. Burghuber (Otto-Wagner Spital, Vienna, Austria); D. Elton, A. Sy, E. McFarland, N. Haase and M. Stout (Palmetto Richland Memorial Hospital, Lexington, SC, USA); W. Tillis, P. Whitten, J. Crabb, K. Hartwig and A. Scott (Peoria Pulmonary Associates, Peoria, IL, USA); B. Levine, J. Ross, D. Baratz and L. Fu (Pulmonary Associates, Phoenix, AZ, USA); E. Cordasco, J. Adamo and J. Botte (Remington-Davis Clinical Research, Columbus, OH, USA); K. Voelker, T. Horiuchi, K. Hurwitz, G. Ferreira and K. Morgan (Sarasota Memorial Hospital, Sarasota, FL, USA); M. Jantz, A. Deem and A. Fox (Shands Hospital - University of Florida, Gainesville, FL, USA); S. Campbell, T. Vincent and W. Shen (Southern Arizona VA Health Care System, Tucson, AZ, USA); S. Hazelrigg and T. Boley (Southern Illinois University, Springfield, IL, USA); W.M. Boomer, J. Goulet and C. Mullins (St Francis Hospital, Tulsa, OK, USA); J. Cicena and P. O'Neill (St Vincent's Hospital Manhattan, New York, NY, USA); G. Criner, J. Travaline, W. Chatila, G. Jones (Temple University Hospital, Philadelphia, PA, USA); F. Herth and R. Eberhardt (Thoraxklinik Heidelberg, Heidelberg, Germany); W. Leeds, G. Fair, L. Ludlow, S. Nicklin and C. Davis (Veritas Clinical Specialties, Topeka, KS, USA); K. Kovitz and S. Ditta (Tulane University Hospital, New Orleans, LA, USA); A. Chan, R. Allen, T. Albertson, B. Morrissey and M. Juarez (UC Davis, Sacramento, CA, USA); P. Germonpre, A. Janssens and W. De Backer (University Hospital Antwerp, Edegem, Belgium); M. Noppen, J. De Mey and M. Meysman (University Hospital AZ-VUB, Brussels, Belgium); G. McLennan, J. Ferguson, A. Ross, K. Sprenger and J. Keating (University of Iowa Medical Center, Iowa City, IA, USA); M. Zgoda, R. Berger, J. McClung and R. Cortes (University of Kentucky, Lexington, KY, USA); M. Krasna, J. Britt, Z. Gamliel and I. Moskowitz (University of Maryland, Baltimore, MD, USA); S. Gay and J. Konkle (University of Michigan Medical Center, Ann Arbor, MI, USA); F. Sciurba, R. Landreneau, M. Crespo, L. Lane, W. Slivka, C. Fuhrman, P. Ferson and C. Witt (University of Pittsburgh Medical Center, Pittsburgh, PA, USA); S. Goodnight-White, S. Soubra, P. Smithwick and K. Velamuri (VA Medical Center, Houston, TX, USA). Other participants: clinical events committee: C. Cooper (University of California, Los Angeles, CA, USA), B. Badduke (Washington Township Medical Foundation, Fremont, CA, USA) and E. Hsiao (Santa Clara Valley Medical Center, San Jose, CA, USA); data safety monitoring board: R. Wise (Johns Hopkins University, Baltimore, MD, USA), B. Celli (Pulmonary Division, Brigham and Women's Hospital, Boston, MA, USA), A. Ciccone (University La Sapienza, Rome, Italy), R. Keenan (Division of Thoracic Surgery, Pittsburgh, PA, USA) and D. Gilman (ICRC, Inc., Reno, NV, USA); CT core laboratory: J. Goldin, M. Brown, M. McNitte-Gray, I. da Costa and J. Ho (University of California, Los Angeles, CA, USA); cost-effectiveness core laboratory: R. Kaplan and T. Ganiats; UCSD Health Outcomes Assessment Program: E. Groessl, J. Harvey and B. Mulligan (University of California, San Diego, CA, USA).

\section{References}

1 Fishman A, Martinez F, Naunheim K, et al. A randomized trial comparing lung-volume-reduction surgery with medical therapy for severe emphysema. N Engl J Med 2003; 348: 2059-2073.

2 Sciurba FC, Rogers RM, Keenan RJ, et al. Improvement in pulmonary function and elastic recoil after lungreduction surgery for diffuse emphysema. N Engl J Med 1996; 334: 1095-1099.

3 Sciurba FC, Ernst A, Herth FJ, et al. A randomized study of endobronchial valves for advanced emphysema. $N$ Engl J Med 2010; 363: 1233-1244.

4 Toma TP, Hopkinson NS, Hillier J, et al. Bronchoscopic volume reduction with valve implants in patients with severe emphysema. Lancet 2003; 361: 931-933.

5 Wan IY, Toma TP, Geddes DM, et al. Bronchoscopic lung volume reduction for end-stage emphysema: report on the first 98 patients. Chest 2006; 129: 518-526.

6 Wood DE, McKenna RJ Jr, Yusen RD, et al. A multicenter trial of an intrabronchial valve for treatment of severe emphysema. J Thorac Cardiovasc Surg 2007; 133: 65-73.

7 Hopkinson NS, Kemp SV, Toma TP, et al. Atelectasis and survival after bronchoscopic lung volume reduction for COPD. Eur Respir J 2011; 37: 1346-1351.

8 Springmeyer SC, Bolliger CT, Waddell TK, et al. Treatment of heterogeneous emphysema using the spiration IBV valves. Thorac Surg Clin 2009; 19: 247-253.

9 Hopkinson NS, Toma TP, Hansell DM, et al. Effects of bronchoscopic lung volume reduction on dynamic hyperinflation and exercise in emphysema. Am J Respir Crit Care Med 2005; 171: 453-460.

10 Celli BR, Cote CG, Marin JM, et al. The body-mass index, airflow obstruction, dyspnea, and exercise capacity index in chronic obstructive pulmonary disease. N Engl J Med 2004; 350: 1005-1012.

11 Martinez FJ, Han MK, Andrei AC, et al. Longitudinal change in the BODE index predicts mortality in severe emphysema. Am J Respir Crit Care Med 2008; 178: 491-499.

12 Ong KC, Earnest A, Lu SJ A multidimensional grading system (BODE index) as predictor of hospitalization for COPD, Chest 2005; 128: 3810-3816.

13 Marin JM, Carrizo SJ, Casanova C, et al. Prediction of risk of COPD exacerbations by the BODE index. Respir Med 2009; 103: 373-378.

14 Cote CG, Celli BR Pulmonary rehabilitation, the BODE index in COPD, Eur Respir J 2005; 26: 630-636.

15 Imfeld S, Bloch KE, Weder W, et al. The BODE index after lung volume reduction surgery correlates with survival. Chest 2006; 129: 873-878. 
Lederer DJ, Thomashow BM, Ginsburg ME, et al. Lung-volume reduction surgery for pulmonary emphysema: improvement in body mass index, airflow obstruction, dyspnea, and exercise capacity index after 1 year. $J$ Thorac Cardiovasc Surg 2007; 133: 1434-1438.

17 Martinez FJ, Foster G, Curtis JL, et al. Predictors of mortality in patients with emphysema and severe airflow obstruction. Am J Respir Crit Care Med 2006; 173: 1326-1334.

18 Casanova C, de Torres JP, Aguirre-Jaíme A, et al. The progression of chronic obstructive pulmonary disease is heterogeneous: the experience of the BODE cohort. Am J Respir Crit Care Med 2011; 184: 1015-1021.

19 Herth FJ, Noppen M, Valipour A, et al. Efficacy predictors of lung volume reduction with Zephyr valves in a European cohort. Eur Respir J 2012; 39: 1334-1342.

20 Strange C, Herth FJ, Kovitz KL, et al. Design of the Endobronchial Valve for Emphysema Palliation Trial (VENT): a non-surgical method of lung volume reduction. BMC Pulm Med 2007; 7: 10.

21 Brown MS, Kim HJ, Abtin FG, et al. Emphysema lung lobe volume reduction: effects on the ipsilateral and contralateral lobes. Eur Radiol 2012; 22: 1547-1555.

22 Pellegrino R, Viegi G, Brusasco V, et al. Interpretative strategies for lung function tests. Eur Respir J 2005; 26: 948-968.

23 Cazzola M, MacNee W, Martinez FJ, et al. Outcomes for COPD pharmacological trials: from lung function to biomarkers. Eur Respir J 2008; 31: 416-469.

24 Puhan MA, Chandra D, Mosenifar Z, et al. The minimal important difference of exercise tests in severe COPD. Eur Respir J 2011; 37: 784-790.

25 Ingenito EP, Wood DE, Utz JP. Bronchoscopic lung volume reduction in severe emphysema. Proc Am Thorac Soc 2008; 5: 454-460.

26 de Oliveira HG, Macedo-Neto AV, John AB, et al. Transbronchoscopic pulmonary emphysema treatment: 1-month to 24-month endoscopic follow-up. Chest 2006; 130: 190-199.

27 Herth FJ, Ernst A, Baker KM, et al. Characterization of outcomes 1 year after endoscopic thermal vapor ablation for patients with heterogeneous emphysema. Int J Chron Obstruct Pulmon Dis 2012; 7: 397-405.

28 Venuta F, Anile M, Diso D, et al. Long-term follow-up after bronchoscopic lung volume reduction in patients with emphysema. Eur Respir J 2012; 39: 1084-1089.

29 Garcia-Rio F, Lores V, Mediano O, et al. Daily physical activity in patients with chronic obstructive pulmonary disease is mainly associated with dynamic hyperinflation. Am J Respir Crit Care Med 2009; 180: 506-512.

30 Morrell NW, Wignall BK, Biggs T, et al. Collateral ventilation and gas exchange in emphysema. Am J Respir Crit Care Med 1994; 150: 635-641.

31 Aziz A, Ashizawa K, Nagaoki K, et al. High resolution CT anatomy of the pulmonary fissures. J Thorac Imaging 2004; 19: 186-191.

32 Gompelmann D, Eberhardt R, Michaud G, et al. Predicting atelectasis by assessment of collateral ventilation prior to endobronchial lung volume reduction: a feasibility study. Respiration 2010; 80: 419-425.

33 Herth FJ, Eberhardt R, Gompelmann D, et al. Radiological and clinical outcomes of using Chartis ${ }^{\mathrm{TM}}$ to plan endobronchial valve treatment. Eur Respir J 2013; 41: 302-308.

34 Ninane V, Geltner C, Bezzi M, et al. Multicentre European study for the treatment of advanced emphysema with bronchial valves. Eur Respir J 2012; 39: 1319-1325.

35 Eberhardt R, Gompelmann D, Schuhmann M, et al. Complete unilateral vs partial bilateral endoscopic lung volume reduction in patients with bilateral lung emphysema. Chest 2012; 142: 900-908. 